Supplement of

\title{
A deep-sea agglutinated foraminifer tube constructed with planktonic foraminifer shells of a single species
}

Paul N. Pearson et al.

Correspondence to: Paul N. Pearson (pearsonp@cardiff.ac.uk)

The copyright of individual parts of the supplement might differ from the CC BY 4.0 License. 


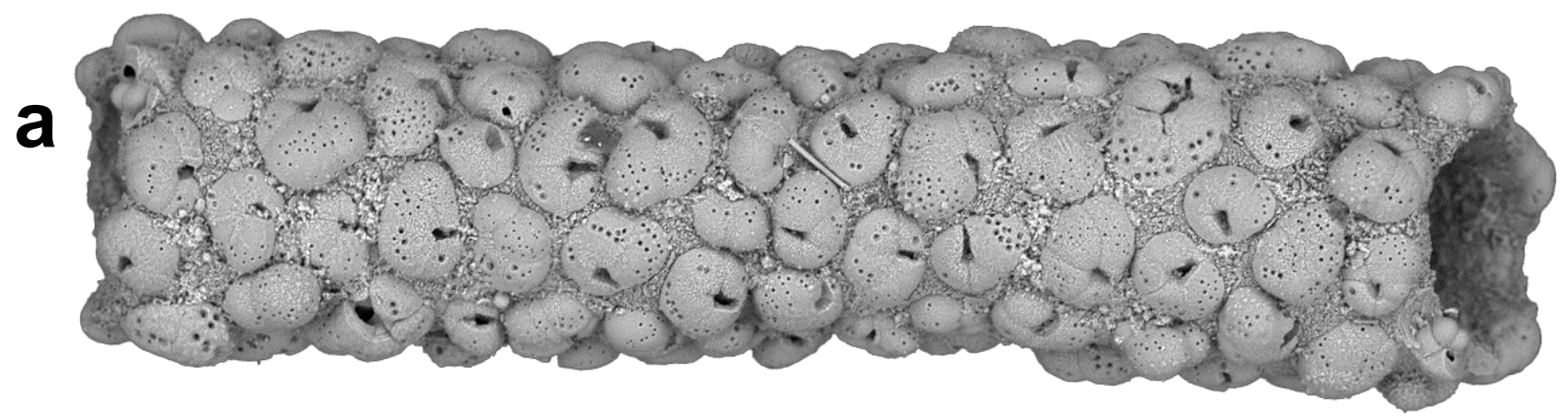

b
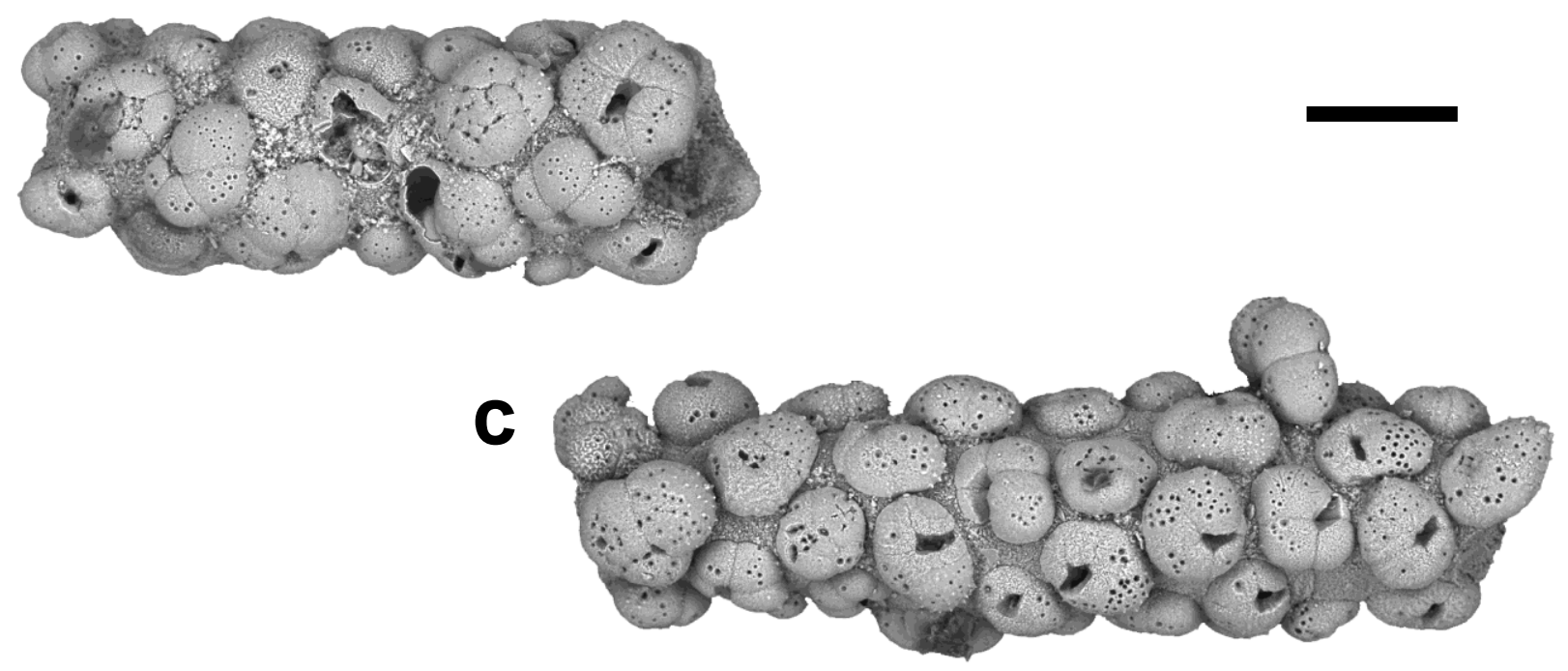

d

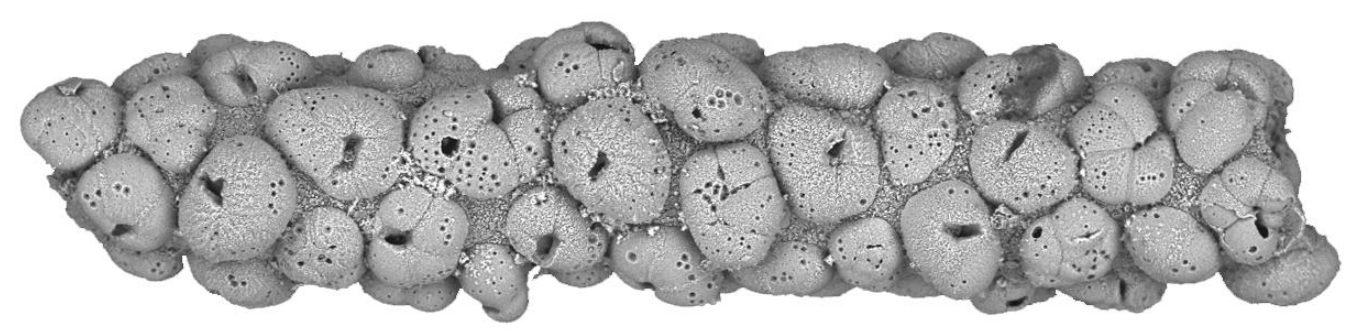

Figure Supplementary 1 
$\underline{\text { Identifier Umbilical Spiral Edge }}$

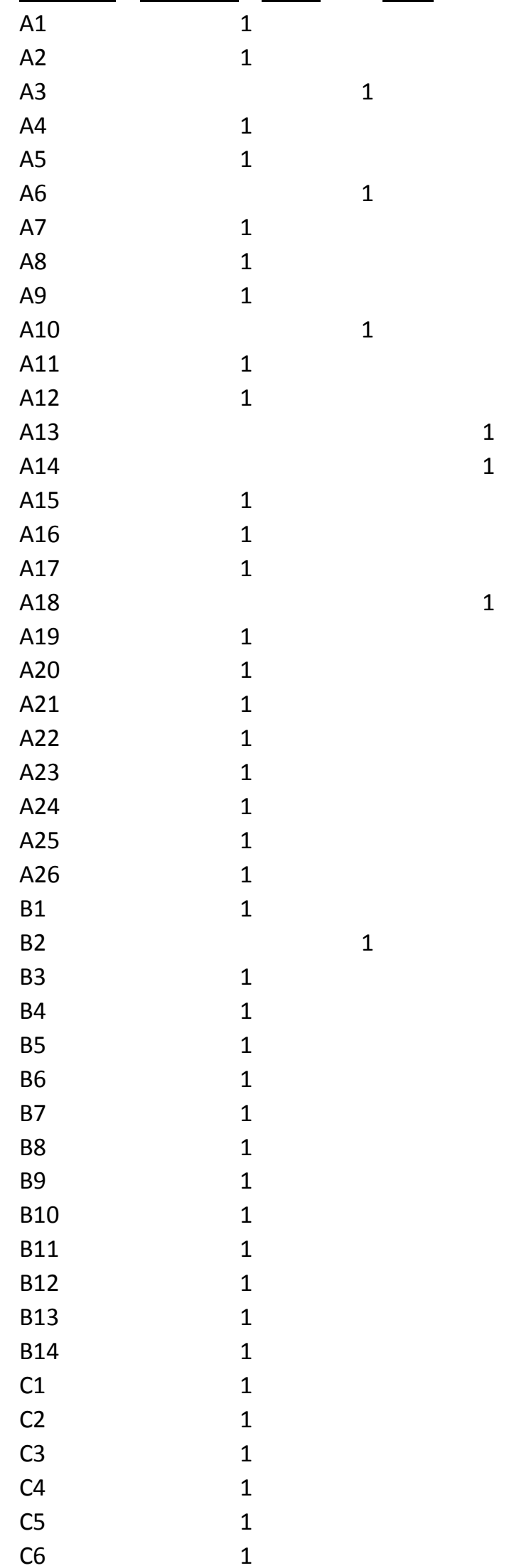




\begin{tabular}{|c|c|c|c|}
\hline C7 & 1 & & \\
\hline C8 & 1 & & \\
\hline C9 & 1 & & \\
\hline C10 & 1 & & \\
\hline C11 & 1 & & \\
\hline C12 & 1 & & \\
\hline $\mathrm{C} 13$ & 1 & & \\
\hline C14 & 1 & & \\
\hline C15 & 1 & & \\
\hline C16 & & 1 & \\
\hline C17 & 1 & & \\
\hline C18 & 1 & & \\
\hline C19 & 1 & & \\
\hline $\mathrm{C} 20$ & 1 & & \\
\hline $\mathrm{C} 21$ & 1 & & \\
\hline $\mathrm{C} 22$ & 1 & & \\
\hline D1 & 1 & & \\
\hline D2 & 1 & & \\
\hline D3 & 1 & & \\
\hline D4 & 1 & & \\
\hline D5 & & 1 & \\
\hline D6 & & 1 & \\
\hline D7 & & 1 & \\
\hline D8 & 1 & & \\
\hline D9 & 1 & & \\
\hline D10 & 1 & & \\
\hline E1 & 1 & & \\
\hline E2 & 1 & & \\
\hline E3 & 1 & & \\
\hline E4 & & 1 & \\
\hline E5 & 1 & & \\
\hline E6 & 1 & & \\
\hline E7 & 1 & & \\
\hline E8 & & & 1 \\
\hline E9 & & 1 & \\
\hline E10 & 1 & & \\
\hline E11 & 1 & & \\
\hline E12 & 1 & & \\
\hline E13 & 1 & & \\
\hline E14 & & & 1 \\
\hline E15 & & 1 & \\
\hline E16 & 1 & & \\
\hline E17 & 1 & & \\
\hline E18 & 1 & & \\
\hline E19 & 1 & & \\
\hline E20 & 1 & & \\
\hline E21 & 1 & & \\
\hline
\end{tabular}




\begin{tabular}{|c|c|c|}
\hline E22 & 1 & \\
\hline E23 & 1 & \\
\hline E24 & & 1 \\
\hline E25 & 1 & \\
\hline E26 & 1 & \\
\hline F1 & 1 & \\
\hline $\mathrm{F} 2$ & 1 & \\
\hline F3 & 1 & \\
\hline $\mathrm{F} 4$ & 1 & \\
\hline F5 & 1 & \\
\hline F6 & 1 & \\
\hline F7 & 1 & \\
\hline F8 & 1 & \\
\hline F9 & 1 & \\
\hline F10 & 1 & \\
\hline F11 & 1 & \\
\hline F12 & & 1 \\
\hline G1 & & 1 \\
\hline G2 & 1 & \\
\hline G3 & 1 & \\
\hline G4 & 1 & \\
\hline G5 & 1 & \\
\hline G6 & 1 & \\
\hline G7 & 1 & \\
\hline G8 & 1 & \\
\hline G9 & 1 & \\
\hline G10 & 1 & \\
\hline $\mathrm{H} 1$ & 1 & \\
\hline $\mathrm{H} 2$ & 1 & \\
\hline \multirow[t]{3}{*}{ H3 } & 1 & \\
\hline & Total umbil & iral Total side \\
\hline & 104 & $14 \quad 5$ \\
\hline
\end{tabular}

